\title{
Morphine injections in the taste aversion paradigm
}

\author{
PHILIP D. FARBER, JUDITH E. GORMAN, and LARRY D. REID \\ Bradley University, Peoria, Illinois 61606
}

\begin{abstract}
In three separate studies, rats were presented with a flavored solution and then injected with one of a variety of doses of morphine in the taste aversion paradigm. Presentations of the flavored water and injections were done 17 times in one study. Doses of from 2 to $20 \mathrm{mg} / \mathrm{kg}$ of morphine were sufficient to suppress drinking of the flavored solution and the extent of the suppression was hardly modified across continuous injections. Furthermore, in one experiment it was demonstrated that injections following the first five injections still had capabilities of suppressing drinking. It made little difference whether the injections were subcutaneously or intraperitoneally given. There were considerable individual differences with respect to extent of suppression of drinking the flavored solution. Some rats showed almost complete suppression but others only a slight suppression.
\end{abstract}

Laboratory animals will press levers to self-inject opioids and other addictive agents (Schuster, 1973; Weeks, 1962). This observation, plus other data, including reports of human addicts (McAuliffe \& Gordon, 1974), suggests that opioids can function as positive reinforcers. Consequently, maintenance of behavior of opioid assimilation is thought to be controlled, in part, by this positive reinforcement and not exclusively by negative reinforcement of relief from withdrawal aversiveness, as suggested by some (Beecher, 1966; Criswell \& Levitt, 1975; Lindesmith, 1938).

Data of Cappell and LeBlanc (1973), LeBlanc and Cappell (1974), and Parker, Failor, and Weidman (1973) are inconsistent with the idea that morphine produces uncomplicated positive affect. Using the now-classic taste aversion paradigm, they have shown that morphine programmed as the unconditioned stimulus established a taste aversion. Yet, of course, morphine assimilation must be more than an unconditioned aversive stimulus. Because of the novelty of the results of studies demonstrating morphine's potentially aversive properties and because of an interest in specifying the affective events associated with a series of morphine injections, we studied morphine in the taste aversion paradigm.

\section{EXPERIMENT I}

The initial studies demonstrating taste aversions with morphine administered the injections only a few times. In this demonstration, flavored water was followed by morphine injections more times while

Research was supported by Grant DA01049 from the National Institute of Drug Abuse, DHEW, and by Bradley University's Board of Research. Phil Farber is now at Midwest Institute of Drug Abuse, University of Wisconsin at Milwaukee. We appreciate the help of Elizabeth Bumagin, Nohra Farber, Mary Overmier, and Nello Rossi. the extent of the aversion to flavored water was measured.

\section{Method}

Subjects and apparatus. The subjects were $\mathbf{3 0}$ (five groups of six) adult (about $350 \mathrm{~g}$ ), male, Sprague-Dawley rats. They were housed individually, in a room with constant lighting, and were given access to food throughout the procedures and water until restricted drinking schedules were begun. Water bottles equipped with ball bearing sipping tubes were used.

Procedure. The subjects were habituated to individual housing for at least 2 days. Then they were given water only once a day, always in the afternoons, $15 \mathrm{~min} /$ day for 6 days. The subjects learned quickly (within a couple of days) to drink a daily ration of water under this regimen.

Daily presentation of a fluid for $15 \mathrm{~min} /$ day was then continued for 42 days and daily consumption tabulated. Every 3rd day, saccharin flavored water (.1\% saccharin) was substituted for the tap water given on all other days. Consequently, there were 14 presentations of the saccharin solution. As soon as possible (always within $5 \mathrm{~min}$ ) after the 15 -min saccharin presentation, each subject was given a $\mathrm{ml} / \mathrm{kg}$ intraperitoneal injection; and for a group of subjects, the injection contained 0,2 , 4,10 , or $20 \mathrm{mg}$ of morphine sulfate in $1 \mathrm{ml}$ of water.

\section{Results and Discussion}

Mean amounts of flavored water consumed by each group (subjects of a given dose) are depicted in Figure 1. Prior to introduction of the flavored water, the subjects drank about 16 to $20 \mathrm{~g}$ of tap water during the 15 -min period. Figure 1 shows that the subjects receiving the carrier of morphine $(0 \mathrm{mg} / \mathrm{kg})$ had a transitory decrease in consumption with the first saccharin and then consumed as much as had previously been consumed of tap water (mean ratio of grams of saccharin solution to mean grams of tap water across the 42 days $=1.01$ ).

Subjects injected with morphine following the opportunity to drink saccharin water markedly decreased their drinking of saccharin across the first four tests, and then their drinking levels gradually increased. A 5 by 14 analysis of variance (ANOVA) 


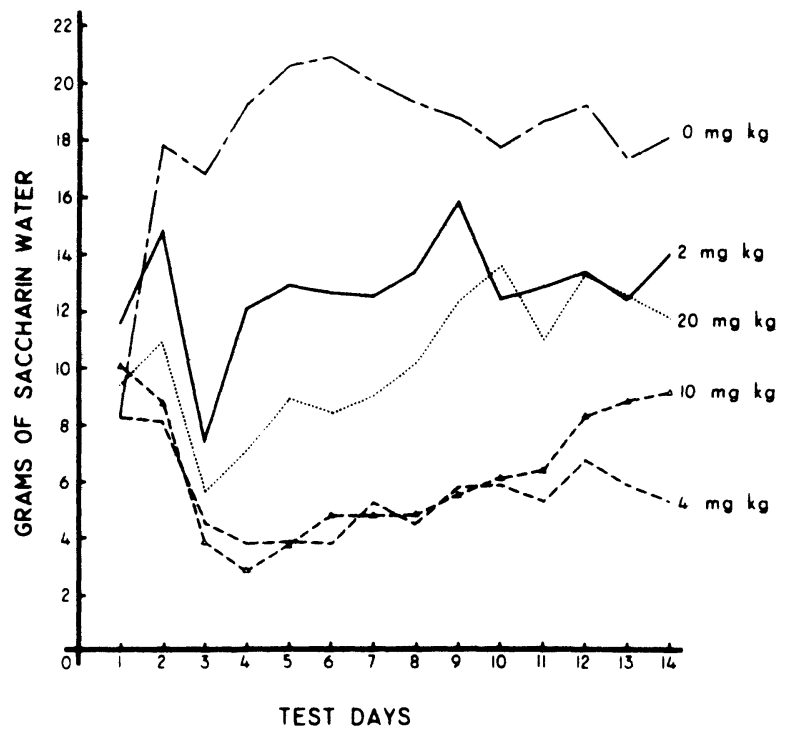

Figure 1. Mean grams of flavored water consumed by each of the groups. Each group received a different dose of morphine as an unconditioned stimulus in a taste aversion paradigm.

having repeated measures of the data from which the means of Figure 1 were derived yielded the following values: $F(4,25)$ for the dose factor $=21.81$, $\mathrm{p}<.01 ; \mathrm{F}(13,325)$ for factor of repeated tests $=6.07$, $p<.01$; and $F(52,325)$ for the interaction $=3.64$, $\mathrm{p}<.01$. Using the approach suggested by Dunnett (as related in Winer, 1971), scores of groups getting morphine were compared to scores of the $0-\mathrm{mg} / \mathrm{kg}$ group on the last test (14th presentation of saccharin water). All morphine groups' scores were reliably different (ps $<.05$ ) from the $0-\mathrm{mg} / \mathrm{kg}$ control group's scores, e.g., $t(4,25)=2.6, p<.05$, for the difference between the $0 \mathrm{mg} / \mathrm{kg}$ and the $2 \mathrm{mg} / \mathrm{kg}$ groups.

It is clear from inspection of Figure 1 that the larger doses did not necessarily produce the most suppression of drinking. Also, there does seem to be a trend for the aversion to wane with continued injections. In general, these data confirm that morphine can serve as an aversive stimulus in the taste aversion paradigm.

\section{EXPERIMENT II}

Results of the first experiment suggested that the aversiveness of the morphine might wane with continued injections, especially with the dose of $20 \mathrm{mg} / \mathrm{kg}$. From the procedures of Experiment I, however, it is not possible to know if only the first few injections are aversive, but the rats continue to avoid because of their failure to extinguish the avoidance response, or if morphine injections continue to be aversive. The procedures of this experiment were designed to address that issue. Also, the dose $20 \mathrm{mg} / \mathrm{kg}$ of morphine was again tested with many injections and tests.

\begin{abstract}
Method
The subjects were 30 (five groups of six) adult (about $290 \mathrm{~g}$ ), male, Sprague-Dawley rats. In general, the subjects were treated as were the subjects of Experiment I. After habituation to housing and development of scheduled drinking, the subjects began the regimen of every third day being presented with the saccharin solution, and this continued for 51 days. Consequently, there were 17 tests for consumption of saccharin solution.

One of the five groups received $0-\mathrm{mg} / \mathrm{kg}$ injections throughout. Two groups received $4 \mathrm{mg} / \mathrm{kg}$ following the first five presentations of saccharin. Then, one of these groups continued to get the 4-mg/ $\mathrm{kg}$ injections throughout the balance of the trials; the other group's injections were terminated with the fifth injection, but their testing for consumption of saccharin was continued. Two groups received $20 \mathrm{mg} / \mathrm{kg}$ of morphine following first five presentations of saccharin; then one group continued to receive the injection and the other group did not get further injections. A comparison between the groups whose injections were terminated, i.e., who were under extinction procedures, to groups whose injections were continued would reveal whether or not the aversiveness of the injections was limited to the first five injections.
\end{abstract}

\section{Results and Discussion}

Results of the tests for consumption of the saccharin solution are depicted in Figure 2. Subjects getting morphine following the first five exposures developed an aversion to drinking the flavored solution. The results of a 3 by 5 ANOVA with repeated measures, with the three groups of the first five exposures across the first five exposures, demonstrate again morphine's capacity to establish a taste aversion: $F(2,27)$ for the group factor $=19.6, p<.01$; $\mathrm{F}(4,108)$ for the repeated tests $=18.5, \mathrm{p}<.01$; and $F(8,108)$ for the interaction $=11.9, p<.01$.

Subjects getting $20-\mathrm{mg} / \mathrm{kg}$ doses of morphine across the days of tests maintained a level of aversion similar to that of the fifth day of tests. Subjects of $20-\mathrm{mg} / \mathrm{kg}$ doses whose injections were terminated on the fifth day gradually drank more and more of the saccharin solution until, by the end of testing, they drank as much as subjects of no morphine. The same relationships held for groups of $4-\mathrm{mg} / \mathrm{kg}$ injections. A 5 by 12 ANOVA having repeated measures was computed across the sixth to the seventeenth tests and yielded an $F(4,25)$ for the group factor $=5.7$, $\mathrm{p}<.01 ; \mathrm{F}(11,275)$ for repeated tests $=7.4, \mathrm{p}<.01$; and $F(44,275)$ for the interaction $=1.8, p<.01$. Using Dunnett's procedure to compare groups to a control group and the scores of the last day of tests, it was found that neither group whose injections were terminated differed from the group of no morphine, but that both groups whose injections were continued did differ reliably from the control group: $\mathrm{t}(4,25)$ for $4 \mathrm{mg} / \mathrm{kg}$ comparison $=3.6, \mathrm{p}<.01$; $\mathrm{t}(4,25)$ for $20 \mathrm{mg} / \mathrm{kg}=4.4, \mathrm{p}<.01$. Furthermore, the two groups of $4 \mathrm{mg} / \mathrm{kg}$, one whose injections were continued and one whose injections were not continued, differed from one another on the last day of testing, $\mathrm{t}(10)=2.5, \mathrm{p}<.05$; as did the two groups of $20 \mathrm{mg} / \mathrm{kg}, \mathrm{t}(10)=4.2, \mathrm{p}<.05$.

If a true poison, such as is used in the typical taste 


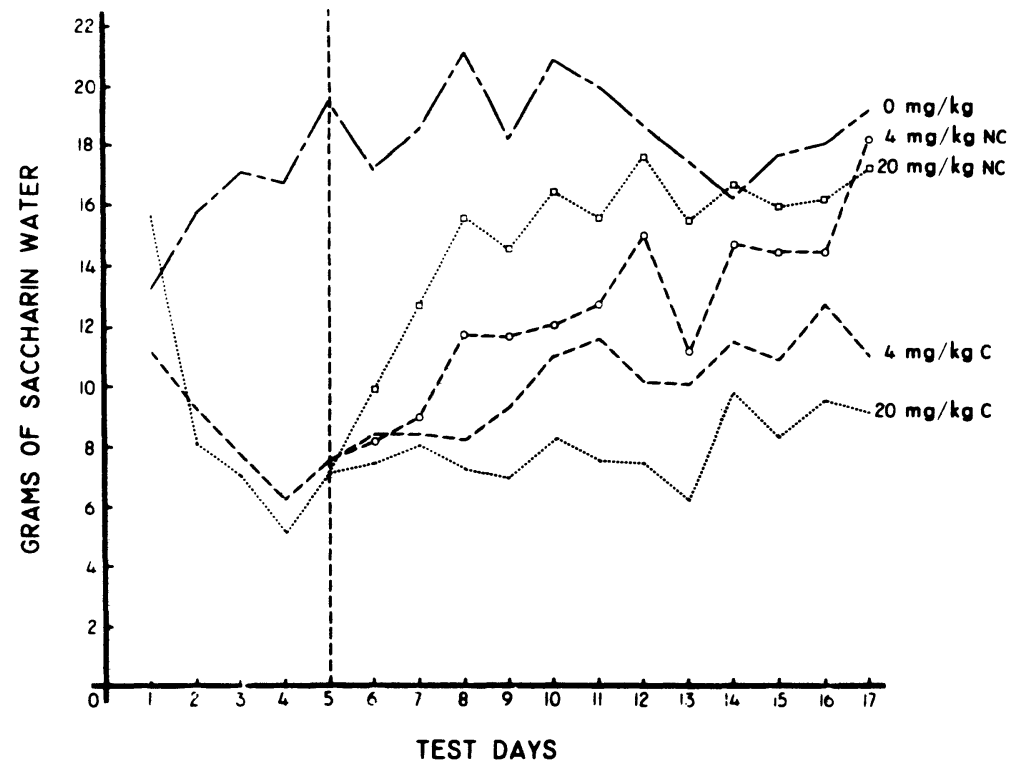

Figure 2. Mean grams of flavored water consumed by each group of rats. Subsequent to the fifth test day, injections were terminated for one-half of rats getting doses of morphine greater than $0 \mathrm{mg} / \mathrm{kg}$. C stands for continued injections; NC stands for not continued injections. aversion paradigm, had been given across 17 days of presentations, it would be expected that the amount of saccharin solution consumed would have been nil. The subjects of morphine injections, although definitely drinking less and thereby demonstrating an aversion, did drink a mean of 8 to $12 \mathrm{~g}$ of saccharin on the last days of testing.

\section{EXPERIMENT III}

In the previous two experiments, intraperitoneal injections (IP) were given, whereas in our other studies (e.g., Rossi \& Reid, in press) assessing affective consequences of morphine, subcutaneous injections (SQ) were given. To ensure that mode of injection was not a significant variable in producing taste aversions, another three groups of rats were tested. The general procedures were the same as those of the previous two experiments, except that some subjects got SQ injections. One group $(n=6)$ got saline IP, another $(\mathrm{n}=6)$ got $10 \mathrm{mg} / \mathrm{kg}$ of morphine IP, and the third $(\mathrm{n}=6)$ got $10 \mathrm{mg} / \mathrm{kg}$ of morphine SQ. The results of this test appear in Figure 3. It can be seen that mode of injection of morphine did not produce a difference, but that morphine, again, regardless of mode of injection, produced a taste aversion.

\section{GENERAL DISCUSSION}

The conclusion from this series of tests is that morphine is an aversive stimulus as indexed by the taste aversion paradigm. Morphine remains an aversive stimulus beyond, at least, five injections, and it is an aversive stimulus regardless of whether the injections are intraperitoneally or subcutaneously given.
The grouped data are clear in supporting the conclusion; however, certain rats' data are interesting. Not all rats show intense aversions, e.g., one subject of Experiment II ( $20 \mathrm{mg} / \mathrm{kg}$, continuous injections) drank a range 8.5 to $15 \mathrm{~g}$ of saccharin water across the 17 tests, and four of the six subjects of that group drank more than $10 \mathrm{~g}$ of saccharin solution on the

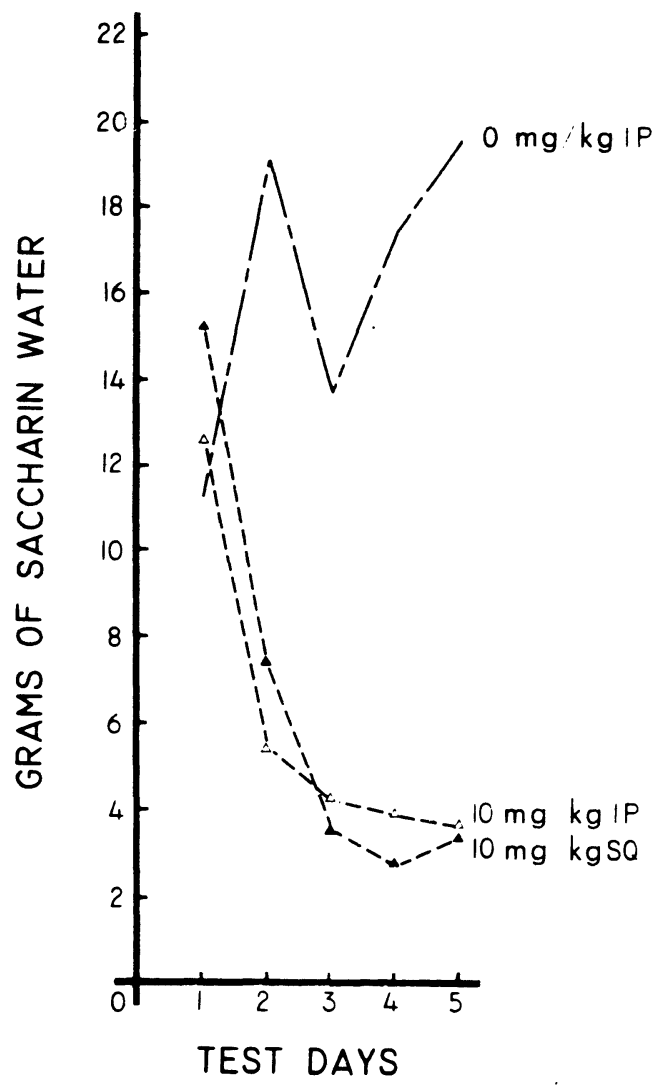

Figure 3. Mean amounts of flavored water consumed by rats getting different kinds of injections. 
last day of testing, and on many days previous to the last day, whereas the others drank hardly any. The relative resistance of some animals to establishing a strong aversion is apparent with the first few injections. These rats are, perhaps, particularly prone to dependency on morphine.

It seems paradoxical that morphine should have such strong initial aversive consequences when the behavior of morphine assimilation can be so easily maintained by the consequences of morphine. Rossi and Reid (in press) demonstrated that morphine injections of $10 \mathrm{mg} / \mathrm{kg} \mathrm{SQ}$, across daily injections, produces a positive affective state from 1 to $2 \mathrm{~h}$ after an injection, as indexed by rats' movement to the place of their morphine experience. The affective state that follows the first morphine injections, then, is probably initial aversiveness, followed shortly by a positive affective state of some duration, followed by a neutral state. With continuance of daily injections, presumably, the initial aversiveness wanes (LeBlanc \& Cappell, 1974), but rather slowly (Experiment II), and the duration of positiveness is shortened (Adams, Lorens, \& Mitchell, 1972; Rossi \& Reid, in press) and eventually there is withdrawal aversiveness subsequent to the positiveness. Casper and Reid (1975) have demonstrated that the contingency of a sequence of initial aversiveness followed by a series of positive events is a sequence of events that will maintain relatively high rates of behavior. Consequently, these fluctuations in affective states following morphine injections do not present a problem for understanding how morphine, as a consequence, can maintain behavior. Knowing the sequence of affective events, however, is the first step in understanding the physiological concomitants of those events.

\section{REFERENCES}

Adams, W. J.. Lorens, S. A., \& Mitchell, C. L. Morphine enhances lateral hypothalamic self-stimulation in the rat. Proc'e'dings of the Society of Experimental Biology and Medicine. 1972. 140. 770-771.

BEECHER. H. K. The use of chemical agents on the control of pain. In R. S. Knighton \& P. R. Dunke (Eds.). Pain. Boston: Little. Broun. 1966.

Cappell, H.. \& LeBlanc, A. E. Punishment of saccharin drinking by amphetamine in rats and its reversal by chlordiazepoxide. Journal of Comparative and Physiological Psychology, 1973, 85. 97-104.

Casper, N. J.. \& Reid, L. D. Complex contingencies. Physiological Psychology. 1975. 3, 9-13.

Criswell. H. E., \& Levitt, R. A. The narcotic analgesics. In R. A. Levitt (Ed.). Psychopharmacology. New York:'Wiley, 1975.

LeBlanc. A. E., \& Cappell, H. Attenuation of punishing effects of morphine and amphetamine by chronic prior treatment. Journal of Comparative and Physiological Psychology. 1974. 87. $691-698$.

Lindesmith. A. R. A sociological theory of drug addiction. The American Journal of Sociology. 1938, 43, 593-613.

McAuliffe. W. E., \& Gordon. R. A. A test of Lindesmith's theory of addiction: The frequency of euphoria among long-term addicts. The American Journal of Sociology, 1974, 79. 795-840.

Parker, L.. Failor, A., \& Weidman, K. Conditioned preferences in the rat with an unnatural need state: Morphine withdrawal. Journal of Comparative and Physiological Psychology' 1973. 82. 294-300.

Rossi. N. A.. \& REID. L. D. Affective states associated with morphine injections. Phy'siological Psychology, in press.

SChuster. C. R. Self-administration of drugs. In L. Goldberg \& F. Hoffmeister (Eds.). Psychic dependence. New York: SpringerVerlag. 1973.

WEEKS, J. R. Experimental morphine addiction: Method for automatic intravenous injections in unrestrained rats. Science. 1962. 138. 14.3-144.

WINER. B. Statistical principles in experimental design (2nd ed.) New York: McGraw-Hill. 1971.

(Received for publication March 11. 1976; revision accepted May 18. 1976.) 